\title{
Identification of persuasive elements in Islamic knowledge website using Kansei engineering
}

\author{
Nor Aziah Daud ${ }^{1}$, Nurul Izzati Aminudin², Fauziah Redzuan ${ }^{3}$, Noraidah Sahari Ashaari ${ }^{4}$, \\ Zurina Muda ${ }^{5}$ \\ ${ }^{1,2,3}$ Faculty of Computer and Mathematical Sciences, Universiti Teknologi MARA, Malaysia \\ ${ }^{4,5}$ Faculty of Information Science and Technology, Universiti Kebangsaan Malaysia, Malaysia
}

\author{
Article Info \\ Article history: \\ Received Sep 30, 2018 \\ Revised Oct 14, 2018 \\ Accepted Nov 19, 2018

\section{Keywords:} \\ Islamic online knowledge \\ Kansei words \\ Kansei engineering \\ Persuasive elements \\ Persuasive system design
}

\begin{abstract}
The global explosions of the internet and direct use by individuals, organizations and Islamic scholars to spread the knowledge and events have witnessed massive growth over the years. The users refuse to use online Islamic websites as references which causes the acceptance rate of the online learning method still low. This paper presents the identifications of persuasive elements in Islamic knowledge website. The objective of this study is to identify the persuasive element using Kansei Engineering (KE) method for online Islamic knowledge website design. Therefore, Kansei words related to online Islamic knowledge were identified. After that, the Kansei words (KWs) were evaluated in order to be used as persuasive elements. Ten specimens of Islamic websites were chosen and evaluated with 30 emotions of KWs. 38 students from one of the public universities accomplished the evaluation experiment. The gathered KWs were then analyzed using multivariate analysis such as Factor Analysis to identify the persuasive elements. Based on Factor Analysis, the finding of this research revealed four main pillars which are credibility-motivated, reliability, Islamic identity and functional. The two additional pillars are updated and belief. The pillars were then compared with the persuasive elements in the previous research. Although there are some limitations and constraint during the conduct of the research, this study also contributes to the design persuasive elements for Islamic website knowledge in the future.
\end{abstract}

Copyright $(0) 2019$ Institute of Advanced Engineering and Science. All rights reserved.

\section{Corresponding Author:}

Nor Aziah Daud,

Department of Information Technology,

Universiti Teknologi MARA,

40450 Shah Alam, Selangor, Malaysia.

Email: aziah@tmsk.uitm.edu.my

\section{INTRODUCTION}

Internet diffusion in Malaysia stands at $67 \%$, making it credible to enhance the utilization of online learning, thereby globalizing the knowledge attainment. Online learning continues to put on view serious issues of low retention rates [1]. Failure to understand the content, user's satisfaction and user's motivation are the factors that contributed to the reason of the dropout in online courses $[1,2]$. Muslims need some references online to learn Islamic knowledge as alternative to face-to-face classes, however Islamic knowledge provided on websites does not meet with the users' expectations and needs [3]. Muslim must continuously learn Islamic knowledge because it is compulsory for a Muslim and to attain success in this life and hereafter. The Islamic websites lack of valid references and the layout is usually difficult to explore [4]. Due to that reason, online Islamic knowledge is refused to be used as reference causing the acceptance rate for the online learning method to be low. 
In order to give a solution to the problem, online learning for Islamic knowledge must accomplish some innovation to the design. Persuasive design has been applied in other domains and is expected to be used as a guide to online learning for Islamic content knowledge. Currently, there are still limited investigations done on how specific persuasive features and functionalities should assimilate within online knowledge as well as in online Islamic knowledge [5]. Thus, the persuasive elements have to be identified using an appropriate method.

Kansei Engineering (KE) is known as a verified method that enables the triggering of emotions and unites them to specific design elements. KE refers to technology that expresses human psychological feeling into design criteria [6]. Kansei means mental function or precisely known as function of the higher brain, and therefore it is suitable to be implied in this situation [7-11]. The process of Kansei begins with collecting sensory-related functions such as feelings, emotions, and intuition, through five senses, which are; vision, hearing, odor, taste and skin sensation [9, 11]. Due to these reasons, KE is selected as the method of this study since $\mathrm{KE}$ is the most appropriate approach in order to meet the objective of this research. Kansei engineering has been used to identify the persuasive elements based on appropriate online website as specimens for the research. The Kansei words related to persuasive element are then recognized. Indisputably, the delivery of the right contents to the users with appropriate design results in effective learning including in online learning [12]. The principle of persuasive technology is as a medium in raising awareness and usage of uncomplicated knowledge website [13, 14].

\section{RESEARCH METHOD}

The method of this research is adopted Kansei Engineering Methodology Type II, - KE System which is adapted from [11], [15]. The phases in Figure 1 show the process involved in this research. The process starts with the theoretical study, identification of specimens and Kansei words followed by the Kansei evaluation, the analysis phase and the design recommendation phase.

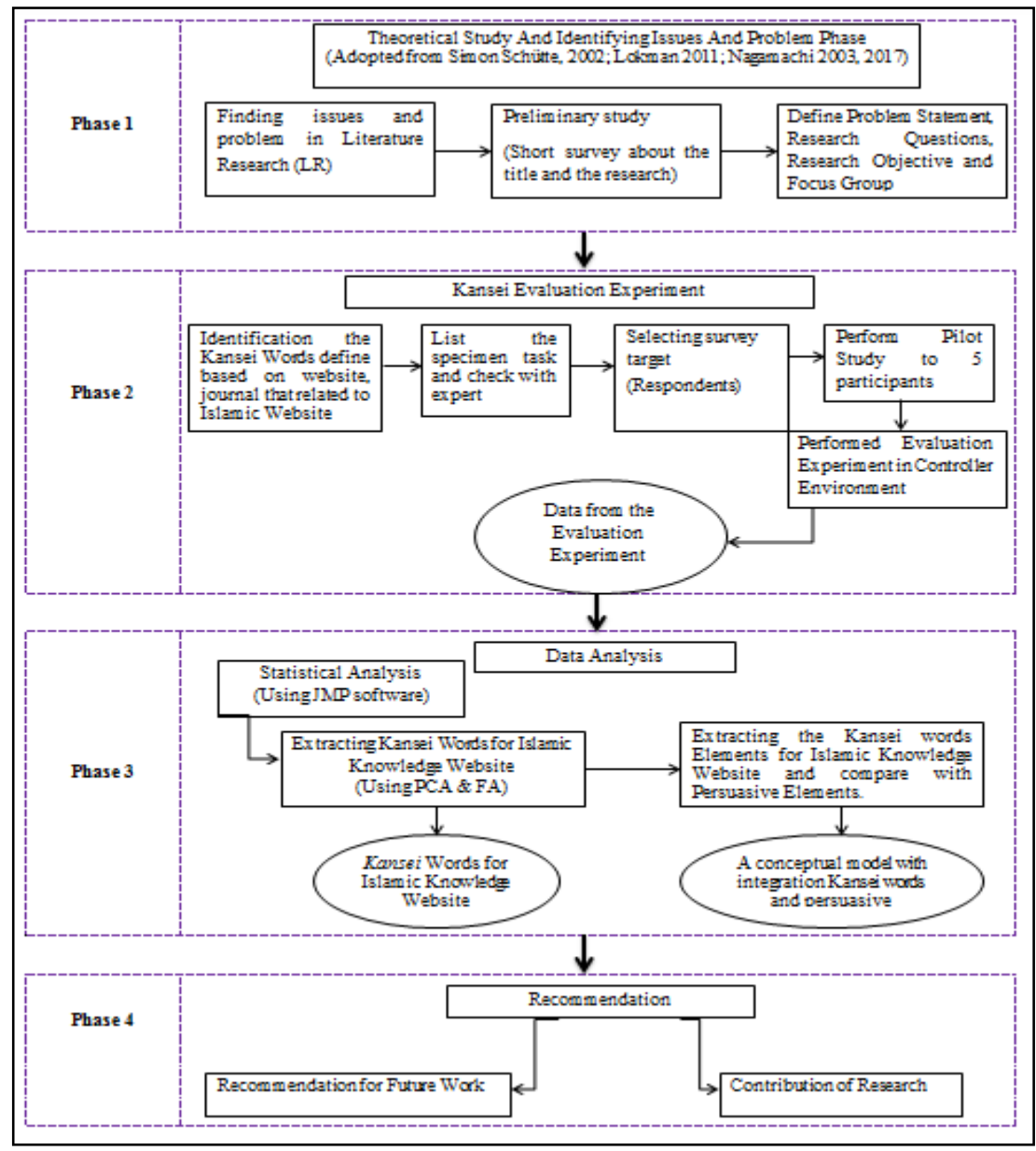

Figure 1. Kansei engineering process 
Phase 1-Determine the problem of the research. As initiation in this research, literature review has been performed in order to identify issues and problems occurred in Islamic online knowledge. A preliminary study was conducted on 30 users from local university using questionnaire. Problem statement, research questions and research objective were defined based on findings from literature and preliminary study. The activities in this phase then identify website specimens, investigate the design elements in which specimen site features are selected. Ten specimens were selected based on the similar theme of the sites.

Phase 2-Identify important emotions and specimens for Islamic online website. Kansei words (KWs) has been chosen based on the relationship between design elements in each specimen. KW is a word consisting of adjectives, nouns or short sentence that applies to guest feedback and can represent the emotions of Muslims on research specimens. 30 emotions that relate to persuasive condition are selected which was adopted from previous research [16].

During the assessment procedure, 28 people were chosen to be the subject of evaluation. According to [17], a total of 20 to 30 people are sufficient to be used as test subjects. All subjects were randomly selected with the requirement that at least they had experience in using Islamic knowledge websites. Before the assessment, all subjects were briefed and advised to complete the assessment test based on their feelings towards the specimens.

Each participant was used by the subject to assess their emotions against each specimen. The participants were given specific time to answer the questions referring to Kansei method, where it took 2 to 3 seconds to answer the questions [10]. Subjects were required to test each specimen given where they need to assess their emotions using 5 Likert scales.

Phase 3-This phase explains the results of the entire Kansei assessment conducted. Data analysis requires several operations that need to be done such as setting up categories, categorizing raw data through coding, tabulation and then depicting statistical conclusions [18]. In this study, data are considered as a requirement of the Islamic knowledge website where they are presented in statistical analysis. Using the JMP statistics analysis software, the data were classified as the most positive website, using Principle Component Analysis (PCA) which is Kansei semantic space. Kansei words are usually shown using Factor Analysis.

Phase 4-The last phase in the process of the investigation methodology is the interpretation of the results which is a combination of Kansei words and persuasive design of the report writing.

\section{RESULTS AND ANALYSIS}

The finding of this research is expected to identify elements of persuasive in association with specific emotion to be used in designing online knowledge for Islamic content. This finding was obtained from Factor Analysis (FA), Principle Component Analysis (PCA) and Partial Least Square (PLS) by using the average evaluation data. FA and PCA with a varimax rotation were performed to identify the Kansei words for this research. From FA, variance analysis result was obtained to determine the most significant factors of emotion as illustrated in Table 1.

Table 1 shows variance analysis. From this table, it is seen that the first factor has the highest variance value of 7.1701818 , representing $23.90 \%$ of the data. The second, third and fourth factors also represent the majority of the factors which contributed $19.55 \%, 17.89$ and $17.04 \%$ of the data respectively. The total contribution of four first factors is $78.38 \%$ of the variability. Thus, Factor 1, Factor 2 Factor 3, and Factor 4 may have dominant influence on emotion semantic space within the domain under investigation. As for the fifth factor which gains $11: 59 \%$, the representation of data may still expand, thus factor 5 is considered as an important factor. The sixth factor and minimum values can be ignored because they are considered as less affected emotional structure. In other words, they can be evaluated as insignificant. The selection of these factors is consistent with the results obtained from the Eigenvalue.

Table 1. Variance analysis

\begin{tabular}{cccc}
\hline Factor & Variance & Percent (\%) & Cumulative Percentage (\%) \\
\hline Factor 1 & 7.1701818 & 23.900606 & 23.90060605 \\
Factor 2 & 5.8648355 & 19.549452 & 43.45005767 \\
Factor 3 & 5.3656565 & 17.885522 & 61.33557935 \\
Factor 4 & 5.113231 & 17.044103 & 78.37968275 \\
Factor 5 & 3.4782819 & 11.594273 & 89.97395566 \\
Factor 6 & 1.2474927 & 4.158309 & 94.13226468 \\
\hline
\end{tabular}

Figure 2 shows the loading factor results of factor analysis after varimax rotation was performed. The results are then arranged in descending order to allow for semantic space observation. A value of approximately 0.6 is considered as the reference value. Based on the results, it can be concluded that the semantic space for online Islamic knowledge are structured based on four main factors or pillars and two 
additional factors. The main pillars are credibility-motivated, reliability, Islamic identity and functional. Meanwhile, the additional pillars are updated and belief.

\begin{tabular}{|c|c|c|c|c|c|c|c|c|c|c|c|}
\hline Emotion & Factor 1 & Emotion & Factor 2 & Emotion & Factor 3 & Emotion & Factor 4 & Emotion & Factor 5 & Emotion & Factor 6 \\
\hline Credibility & 0.8964235 & Reliability & 0.86727876 & Islamic identity & 0.93037 & Functional & 0.83668 & Updated & 0.89901 & Belief & 0.714 \\
\hline Standard & 0.8655353 & Attractiveness & 0.85382778 & Simple & 0.87534 & Good Impression & 0.73336 & Relevance & 0.79967 & Ease of access & 0.39951 \\
\hline Motivate & 0.8504832 & Interactivity & 0.81818408 & Ethical value & 0.72427 & Acceleration & 0.68829 & Ease of access & 0.64381 & Usable & 0.33318 \\
\hline Confident & 0.7498111 & Good layout & 0.64389182 & \begin{tabular}{|l|l|} 
& Consistency \\
\end{tabular} & 0.6334 & Usable & 0.65212 & Consistency & 0.47752 & Legitimacy & 0.2442 \\
\hline Authority & 0.7444328 & Easy to find & 0.53409358 & Iman & 0.49035 & Good information & 0.57175 & Easy to find & 0.44777 & Iman & 0.19913 \\
\hline Trust & 0.7394486 & Good Quality & 0.53176849 & Relevance & 0.46061 & Iman & 0.52396 & Acceleration & 0.39275 & Islamic identity & 0.19714 \\
\hline Iman & 0.6148831 & Usable & 0.47205713 & 3 Confident & 0.43269 & Belief & 0.43065 & Good byout & 0.29506 & Acceleration & 0.16692 \\
\hline Good Quality & 0.5791251 & Good explain & 0.45615817 & Good layout & 0.41951 & Ethical value & 0.42713 & Legitimacy & 0.29033 & Simple & 0.13523 \\
\hline Acceleration & 0.4731785 & Converience & 0.44010196 & 6 God explain & 0.39259 & Good Quality & 0.42581 & Authority & 0.26018 & Functional & 0.1294 \\
\hline
\end{tabular}

Figure 2. Partial view of the factor analysis of the kansei words

The first pillar, credibility-motivated includes the Kansei words such as Credibility, Standard, Motivate, Legitimacy, Confident, Authority, Trust, Easy to find, and Iman. The second pillar includes the Kansei words such as Reliability, Attractiveness, Interactivity, Satisfied and Good layout, while the third pillar includes the Kansei words such as Islamic identity, Simple, Ethical value, Good information and Consistency. The forth pillar includes the Kansei words such as Functional, Good Impression, Acceleration, Convenience and Usable. The first additional pillar includes Updated, Relevance and Ease of access whereas the second additional pillar includes only one Kansei word which is Belief.

Figure 3 shows the two-dimensional representation matrix for factor load of a certain number of components. The loading label loads the variable for 30 Kansei words. To identify emotions, the investigation was conducted by PCA to determine the emotional structure of the specimen. The positive words show on the right of $\mathrm{x}$-axis, while negative words are shown towards the left of $\mathrm{x}$-axis. The positive and negative numbers in each axis plots do not represent positive or negative values, but they represent semantic dimension. PCA is one of the important analytical approaches that allow the reduction of the dimensions at little as possible to understand the meaning of data. At the top part of y-axis, emotional words that have large positive load are Updated credibility, Relevance and Legitimacy.

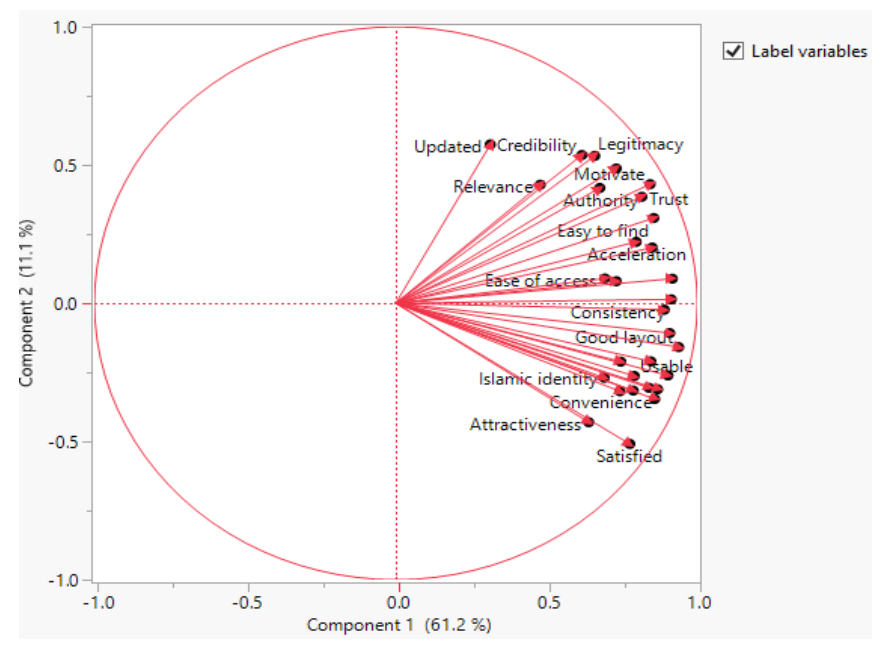

Figure 3. PCA component analysis of kansei words

As seen in Figure 4, based on the dimension of Factor 1, credibility-motivated and Factor 2, reliability, specimens $\mathrm{J}, \mathrm{I}$ and $\mathrm{C}$ are more credibility-motivated and have more reliability. These three specimens' website contents are found to have high positive emotions based on 30 Kansei words. According to the Semantic Kansei space of credibility and reliability, specimens J, I and C can be the appropriate design 
elements for Kansei's emotions. Figure 5 shows websites chosen as specimens and the alphabet A to J represents the specimen.

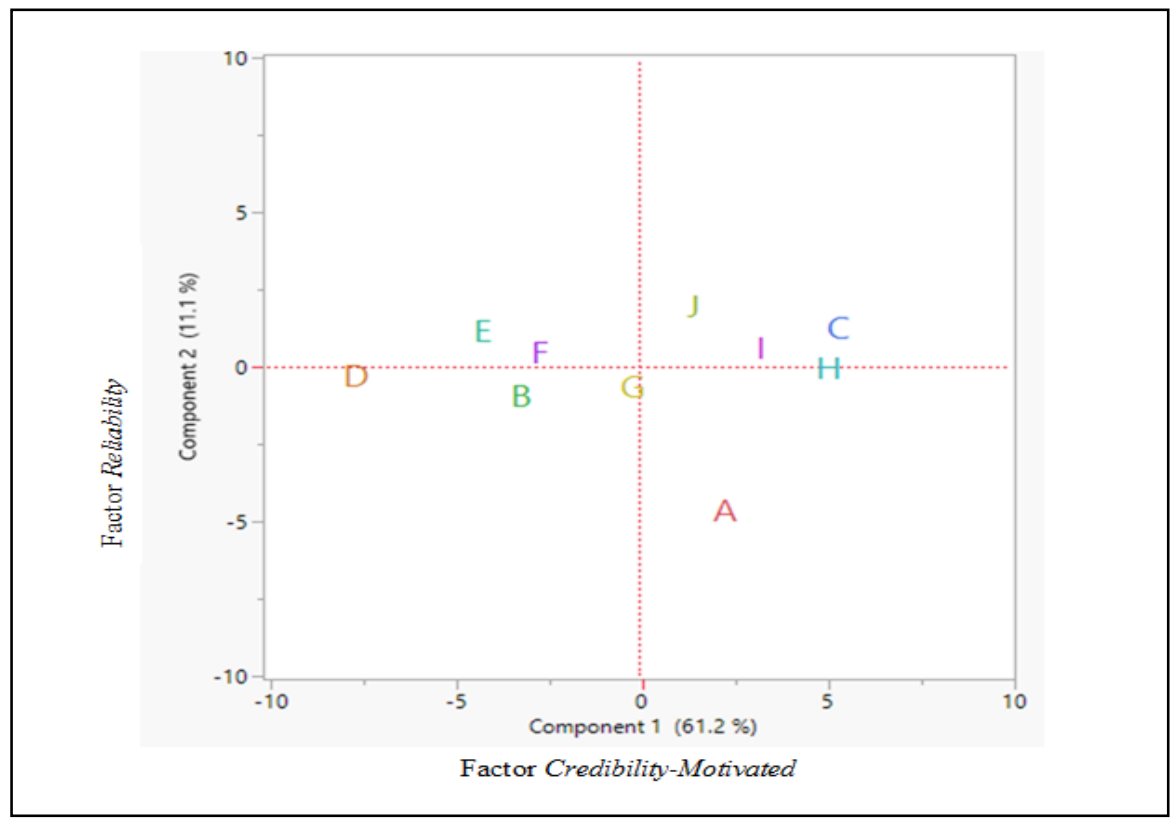

Figure 4. Principle component analysis of specimens based on credibility-motivated and reliability

\begin{tabular}{|rr|l|}
\hline A & 1 & W1 - Portal Rasmi Zakat Pahang \\
\hline C & 2 & W2-Portal Rasmi Zakat Selangor \\
\hline D & 3 & W3-Portal Rasmi Zakat Kelantan \\
\hline E & 4 & W4- Portal Rasmi Zakat Sarawak \\
\hline F & 5 & W5-Portal Rasmi Zakat Pulau Pinang \\
\hline G & 6 & W6-Portal Rasmi Zakat Kedah \\
\hline H & 7 & W7-Portal Rasmi Zakat Negeri Sembilan \\
\hline I & 8 & W8-Portal Rasmi Zakat Wilayah Persekutuan \\
\hline J & 9 & W9-Portal Rasmi Zakat Terengganu \\
\hline B & 10 & W10-Portal Rasmi Zakat Perak \\
\hline
\end{tabular}

Figure 5. Website and specimen numbers

Based on FA result, it can be concluded that the semantic space for Kansei words on Islamic online knowledge are structured based on four main pillars and two additional factors. The main pillars are credibility-motivated, reliability, Islamic identity and functional. Meanwhile, the additional pillars are defined as updated and belief. Further to that, this research has found out the integration between Kansei words and persuasive elements for Islamic online knowledge.

By using the Kansei engineering, this study has developed a model to summarize finding of the study and shown as research model in Figure 6. There are some persuasive elements that are selected to be used in the design. Other than that, this research has identified three new persuasive elements suggested to be used in designing Islamic knowledge website which are; Acceleration, Islamic identity and Iman. These new persuasive elements are hoped to enhance the design of Islamic online knowledge websites to make the design more persuasive which will trigger users' emotion towards gaining Islamic knowledge through online applications. Based on previous studies, there are 15 existing elements which are similar with existing persuasive elements from the findings of this research. 


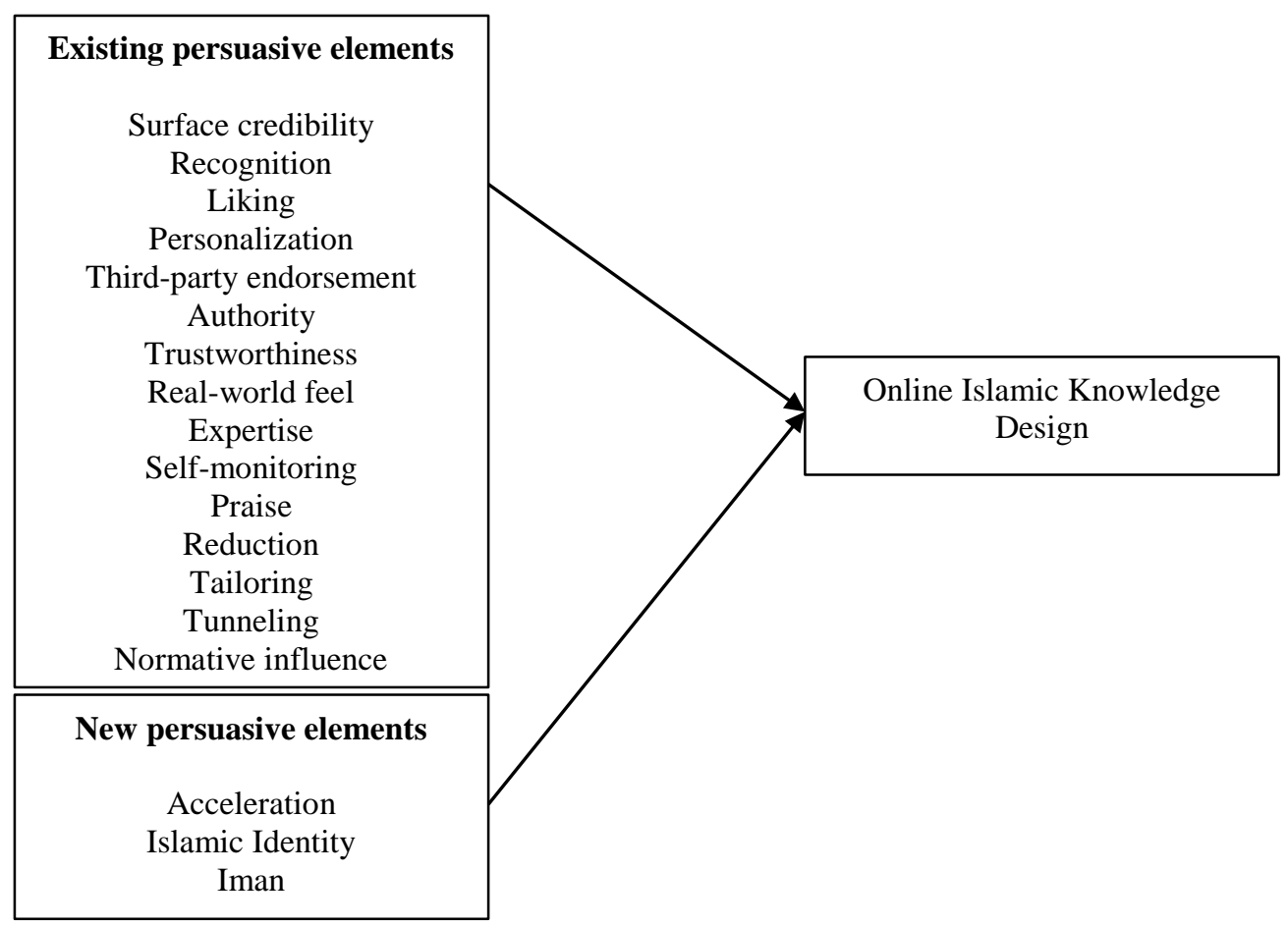

Figure 6. Research model

\section{CONCLUSION}

This paper has presented persuasive elements in Islamic knowledge website. Based on the findings, the objectives of this research have been achieved. First, there are four main pillars and two additional pillars that refer to the emotions which is the structure of semantic space for online Islamic knowledge. The main pillars are credibility-motivated, reliability, Islamic identity and functional. Meanwhile, the additional pillars are updated and belief.

The important emotions for online Islamic knowledge based on the first pillar are Credibility, Standard, Motivate, Legitimacy, Confident, Authority, Trust, Easy to find, Iman and Good Quality. The second pillar includes Reliability, Attractiveness, Interactivity, Satisfied and Good Layout, whereas the third pillar includes Islamic identity, Simple, Ethical value, Good information and Consistency. The forth pillar includes Functional, Good Impression, Acceleration, Convenience and Usable. The first additional pillar includes Updated, Relevance and Ease of access, while the second additional pillar is Belief.

The results from the research have identified fifteen Kansei words that have been chosen using KE method similar with persuasive element in previous research on persuasive. The research also found the three new Kansei words that can be used as persuasive elements for online Islamic knowledge. Overall, the findings of this research is hoped to help in design and development of online Islamic knowledge such as website. This research is also hoped to be a starting effort providing a guideline for other researchers to establish many types of research related to online approach and Islamic knowledge. The identification of the persuasive elements for design online Islamic knowledge website hopefully can increase the acceptance rate from users

\section{ACKNOWLEDGEMENTS}

The authors would like to thank to the Ministry of Education Malaysia and also to the Research Management Institute, Universiti Teknologi MARA (UiTM) for the research support, their valuable and input to the project.

\section{REFERENCES}

[1] Bawa, P. Retention in Online Courses : Exploring Issues and Solutions-A Literature Review. SAGE Open. 2016. 
[2] Hart, C. Factors Associated with Student Persistence in an Online Program of Study: A Review of the Literature. Journal of Interactive Online Learning, 11(1), 19, 2012.

[3] Azizan, N, Alahoul, M.R, Alwi, N.H, Mohd Zarif, MM. Islamic Knowledge: Factors Effective Islamic Knowledge Transfer For Visually Impaired Users Via Malaysia E-learning Websites. 2016.

[4] N. A. Daud, F. Redzuan, Z. A. Nasruddin, N. S. Ashaari and Z. Muda, "Persuasive web design for online islamic education," 2017 6th International Conference on Electrical Engineering and Informatics (ICEEI), Langkawi, 2017, pp. 1-6.

[5] Lokman, A. M, Nagamachi, M. Kansei Engineering Procedures: Kansei Engineering Type II. In A. B. Badiru (Ed.), Innovations of Kansei Engineering (p.50). New York: CRC Press Taylor \& Francis Group. 2017.

[6] Nagamachi, M. Kansei Engineering and Its Method. Management System,1992, 2 (2), 97-105.

[7] Ishihara, S, Ishihara, K, Nagamachi, M. Analysis of Individual Differences in Kansei Evaluation Data Based on Cluster Analysis. Kansei Engineering International, 1993, 1.1: 49-58.

[8] Harada, A. On the Definition of Kansei. In Modeling the Evaluation Structure of Kansei Conference. 1998, Volume 2, page 22.

[9] Yoshikawa, A. Subjective information processing: Its foundation and applications. Biomedical Soft Computing and Human Sciences, 2000, Vol. 6(1), 75-83

[10] Lokman A.M. Design \& Emotion: The Kansei Engineering Methodology. Vol. 1, Issue 1, 2010

[11] Nagamachi, M. Lokman, A. M. Innovations of Kansei Engineering. (A. B. Badiru, Ed.). New York: CRC Press Taylor \& Francis Group. 2011.

[12] Krishnan, P, Vanitha, V. An Integrated Framework to Enhance Performance of Online Students, 2016 (August).

[13] Fogg B.J. How to Motivate \& Persuade Users. 2013.

[14] Fogg, B.J. BJ Fogg's Behavior Model, Stanford University, www.behaviormodel.org/. 2009.

[15] Zubir S, Redzuan F. Evaluating Students' Emotional Response in Mobile Learning Using Kansei Engineering. In: Lokman A., Yamanaka T., Lévy P., Chen K., Koyama S. (eds) Proceedings of the 7th International Conference on Kansei Engineering and Emotion Research 2018. KEER 2018. Advances in Intelligent Systems and Computing, vol 739. Springer, Singapore. 2018.

[16] F. Redzuan, A. M. Lokman and Z. A. Othman, "Kansei semantic space for emotion in online learning," $20143 \mathrm{rd}$ International Conference on User Science and Engineering (i-USEr), Shah Alam, 2014, pp. 168-173.

[17] Nagamachi, M. The story of Kansei Engineering (in Japanese), 2003, (Vol. 6). Tokyo: Japanese Standards Association.

[18] Kothari, C.R. Research Methodology Methods and Techniques. 2004. 2nd Edition, New Age International Publishers, New Delhi. 